\title{
A Study of P-Type Ohmic Contacts to InAlAs/InGaAs Heterostructures
}

R. D. Briggs, A. J. Howard, A. G. Baca, M. J. Hafich and G. A. Vawter

Sandia National Laboratories

Center for Compound Semiconductor Technology

Albuquerque, NM 87185-0603

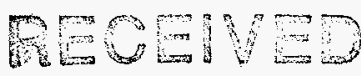

APQ 0896

Optical modulators operating at near-infrared wavelengths are of interest for a variety of

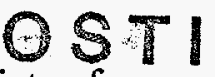
applications including bi-directional communications and optical interconnects. The fabrication of $1.06 \mu \mathrm{m}$ and $1.32 \mu \mathrm{m}$ operating wavelength strained-layer-superlattice vertical-cavity optoelectronic modulators requires the formation of a p-type ohmic contact to the InAlAs/InGaAs quarter-wave bottom mirror stack. In this study, BeAu and TiPtAu p-type ohmic contact metallization schemes were evaluated for use on molecular beam epitaxy (MBE) grown $\mathrm{In}_{.10} \mathrm{Al}_{.90} \mathrm{As} / \mathrm{In}_{.12} \mathrm{Ga}_{.88} \mathrm{As}$ and $\mathrm{In}_{.32} \mathrm{Al}_{.68} \mathrm{As} / \mathrm{In}_{.33} \mathrm{Ga}_{.67} \mathrm{As}$ device heterostructures. Recessed and nonrecessed transmission line measurement (TLM) structures were fabricated and evaluated as a function of rapid thermal anneal (RTA) temperatures over the range of $360^{\circ} \mathrm{C}-420^{\circ} \mathrm{C}$. Atomic force microscopy (AFM) was used to determine the surface morphology of each sample for evidence of metal or material degradation. For contacts directly on InGaAs layers, TiPtAu contacts had relatively high specific contact resistance values of $\rho_{c} \sim 3 \times 10^{-4} \Omega \mathrm{cm}^{2}$ and displayed no dependance on the anneal. The BeAu contacts had minimum specific contact resistance values of $\rho_{c}$ $\sim 5 \times 10^{-7} \Omega \mathrm{cm}^{2}$ but showed evidence of degradation at higher temperatures. Contacts directly made to InAlAs layers had minimum specific contact resistances of $\rho_{c} \sim 4 \times 10^{-5} \Omega \mathrm{cm}^{2}$ and were improved slightly with the addition of a thin GaAs layer.

\section{DISCLAIMER}

\begin{abstract}
This report was prepared as an account of work sponsored by an agency of the United States Government. Neither the United States Government nor any agency thereof, nor any of their employees, makes any warranty, express or implied, or assumes any legal liability or responsibility for the accuracy, completeness, or usefulness of any information, apparatus, product, or process disclosed, or represents that its use would not infringe privately owned rights. Reference herein to any specific commercial product, process, or service by trade name, trademark, manufacturer, or otherwise does not necessarily constitute or imply its endorsement, recommendation, or favoring by the United States Government or any agency thereof. The views and opinions of authors expressed herein do not necessarily state or reflect those of the United States Government or any agency thereof.
\end{abstract}




\section{DISCLAIMER}

Portions of this document may be illegible in electronic image products. Images are produced from the best available original document. 


\section{INTRODUCTION}

Optical modulators operating at near infrared wavelengths of $1-1.6 \mu \mathrm{m}$ have received considerable attention for use in bi-directional satellite communications, remote monitoring of hositile environments and optical interconnects. Several strained-layer-superlattice vertical-cavity reflection and transmission modulators have been developed which operate at 1.06 and $1.32 \mu \mathrm{m}$ wavelengths for implementation in systems using commercial Nd:YAG solid state lasers[1-3]. These devices require the growth of relatively thick (In,Al,Ga)As buffer layers on GaAs substrates to provide an appropriate lattice constant for subsequent growth of the active device structure. Low-doped ternary InAlAs/InGaAs multilayers with precisely controlled compositional values and thicknesses are then grown to create the quarter-wave mirror stacks and cavity region which provide reflectance or transmission mode operation at the desired wavelength. The highest quality material with minimization of dislocations and cross-hatching is achieved by using molecular beam epitaxy (MBE) at low temperatures $\left(-400^{\circ} \mathrm{C}\right)[4]$. For optimal device performance, it is necessary to make metal contact directly to the quarter-wave mirror stacks.

The purpose of this work is to characterize the performance of BeAu and TiPtAu contacts deposited on p-type InGaAs and InAlAs materials for use with optoelectronic devices. The effects of rapid thermal anneal (RTA) temperature variations over the range of $360^{\circ} \mathrm{C}$ to $420^{\circ} \mathrm{C}$ on specific contact resistance and surface morphology are investigated. A maximum anneal temperature of $420^{\circ} \mathrm{C}$ is prescribed to prevent damage to the growth structures which may create an undesired shift in the operating wavelength or other anomalies. Atomic force microscopy (AFM) has been shown to be a useful tool in characterization of integrated circuit fabrication processes.[5] In this study it is used to evaluate the surface of the metallization and detect evidence of metal or epitaxial degradation which may prohibit optimal device performance.

\section{EXPERIMENT}

Transmission modulators operating at $1.06 \mu \mathrm{m}$ and $1.32 \mu \mathrm{m}$ wavelengths employ lower quarter-wave mirror stacks which are comprised of a periodic superlattice with relatively thick ( $100 \mathrm{~nm}$ ) InAlAs and InGaAs layers. The structures investigated in this experiment were designed 
to have the same material compostion and doping as the mirror stacks but were grown with increased thicknesses to provide a worst-case scenario and eliminate the difficulties in determining the interactions between layers. For the $1.06 \mu \mathrm{m}$ device, a $2.0 \mu \mathrm{m}$ thick $\operatorname{In}_{.12} \mathrm{Ga}_{.88} \mathrm{As}$ buffer was grown on a semi-insulating GaAs substrate followed by $500 \mathrm{~nm}$ thick layers of $\operatorname{In}_{.12} \mathrm{Ga}_{.88} \mathrm{As}$ and $\mathrm{In}_{.10} \mathrm{Al}_{.90} \mathrm{As}$ and a $5 \mathrm{~nm}$ GaAs cap layer. For the $1.32 \mu \mathrm{m}$ device, a $3.0 \mu \mathrm{m}$ thick graded InGaAlAs buffer was grown on a semi-insulating GaAs substrate followed by $500 \mathrm{~nm}$ thick layers of $\mathrm{In}_{33} \mathrm{Ga}_{.67} \mathrm{As}$ and $\mathrm{In}_{.32} \mathrm{Al}_{.68} \mathrm{As}$ and a $5 \mathrm{~nm}$ GaAs cap layer. For both wafers, the InGaAs/InAlAs and $\mathrm{GaAs}$ cap layers were each Be doped to $3 \times 10^{18} \mathrm{~cm}^{-3}$. Three separate process iterations with slight variations were made to allow the study of contact performance on individual structural layers. The transmission line measurement (TLM) structures for the first sample set were fabricated on each structure as-grown using a two mask set and standard photolithography. The first mask defined the TLM metallization using a lift-off process and the second mask defined a mesa isolation to restrict the current to flow only between the contacts. The contact pads on the TLM structures were $100 \mu \mathrm{m}$ wide and $50 \mu \mathrm{m}$ long and were spaced at distances of $3,5,9,13$, and $20 \mu \mathrm{m}$. On half of the first set of samples, $200 \mathrm{~nm}$ of BeAu (2\% Be by weight) was deposited by thermal evaporation followed immediately by a $10 \mathrm{~nm}$ of $\mathrm{Ti}, 30 \mathrm{~nm}$ of $\mathrm{Pt}$, and $200 \mathrm{~nm}$ of $\mathrm{Au}$ electron-beam evaporated layer. The TiPtAu layer was neccesary for good wire bond adhesion during device packaging and provided pads which would not delaminate during device probing[6]. The other half of the sample was metallized with only $10 \mathrm{~nm}$ of $\mathrm{Ti}, 30 \mathrm{~nm}$ of $\mathrm{Pt}$, and $200 \mathrm{~nm}$ of Au. Mesas were then patterned and etched in a $\mathrm{HCl}: \mathrm{H}_{2} \mathrm{O}_{2}: \mathrm{H}_{2} \mathrm{O}$ solution. RTA was performed on pieces of each sample in an Addax AET RTA at 360,400 , and $420^{\circ} \mathrm{C}$ for $30 \mathrm{sec}$. The contact pads for the second sample set were recessed into the first InAlAs layer of each device structure. This was accomplished by performing a shallow etch with a $\mathrm{H}_{3} \mathrm{PO}_{4}: \mathrm{H}_{2} \mathrm{O}_{2}: \mathrm{H}_{2} \mathrm{O}$ solution immediately prior to metal deposition using the same contact pad photolithography for a mask. The metals were then immediately deposited into the recess and the process continued as stated above. The third set of samples were first subjected to a chlorine reactive ion-beam etch to remove the first GaAs and InAlAs layers of each structure. Laser interferometry was used to stop the etch on the InGaAs layer and the TLM structures were then fabricated on this layer using the standard process. 
The surface morphology of the contacts on each of the samples were examined with a Digital Instruments Dimension $3000 \mathrm{AFM}$ operating in tapping mode with $\mathrm{Si}_{3} \mathrm{~N}_{4}$ tips. Values of average rms roughness were generated from 256 samples on a $10 \quad 10 \mu \mathrm{m}^{2}$ scan size using the system software. Contact resistances were measured using the standard linear transmission line model method with a four point probe measurement system to eliminate the probe contact resistance.[7] All contact spacings were verified by inspection with a scanning electron microscope. The minimum contact resistance and sheet resistance were derived from a plot of the least squares fit to the measured contact resistance data versus contact spacing. It was not possible to obtain reliable end resistance measurements for the long contact conditions of our mask set where the contact lengths were much greater than the transfer length. This forced the assumption that the sheet resistance under the contact was equal to the sheet resistance of the epitaxial layer between the contacts in our calculations of the specific contact resistance.

\section{RESULTS AND DISCUSSION}

\section{(a) $1.32 \mu \mathrm{m}$ Device Structure}

A comparison of the specific contact resistances as a function of RTA temperature for contacts to the $1.32 \mu \mathrm{m}$ device structure is shown in Figure 1. The TiPtAu contacts exhibited nonohmic behavior when deposited on the GaAs/InAlAs and when recessed into the InAlAs layers. The TiPtAu contacts to the InGaAs layer were ohmic as deposited $\left(\rho_{c}=5.54 \times 10^{-4} \Omega \mathrm{cm}^{2}\right)$ but showed little improvement after RTA and virtually no dependace upon the RTA anneal temperature. The lowest specific contact resistance achieved with the TiPtAu contacts was $\rho_{c}=3.37 \times 10^{-4}$ $\Omega \mathrm{cm}^{2}$. Lower specific contact resistances have been observed for TiPtAu and TiPt on similiar materials (ie. $\mathrm{p}$ - $\operatorname{In}_{.53} \mathrm{Ga}_{{ }_{47}}$ As lattice matched to $\mathrm{InP}$ ) using pre-cleaning techniques and higher RTA temperatures, however, these processes may induce material defects in our devices which could cause performance degradation $[8,9]$. The BeAu contacts had specific contact resistances which were orders of magnitudebetter than the TiPtAu contacts. The BeAu contacts deposited on the GaAs cap and recessed into the InAlAs of the $1.32 \mu \mathrm{m}$ device structure produced minimum values of $\rho_{\mathrm{c}}=3.5 \times 10^{-5} \Omega \mathrm{cm}^{2}$ and $\rho_{\mathrm{c}}=1.09 \times 10^{-5} \Omega \mathrm{cm}^{2}$ at $400^{\circ} \mathrm{C}$, respectively. The degradation of 
contact performance at higher anneal temperatures is consistant with previous reports on similiar materials and has commonly been attributed to spikes and spatial composition problems with the Au-based alloys[10,11]. In contrast, the specific contact resistance of the BeAu contacts deposited on the InGaAs layers continued to decrease with increasing anneal temperature and reached a minimum of $\rho_{c}=5.81 \times 10^{-7} \Omega \mathrm{cm}^{2}$ at $420^{\circ} \mathrm{C}$. However, an examination of the surface morphology of the BeAu contacts suggested that the metal/semiconductor interface was severely damaged which could have been a result of undesirable In segregation or layer intermixing reported previously $[4,12]$.

A comparison of the average $\mathrm{mms}$ roughness of the contact surfaces as a function of anneal temperature is shown in Figure 2. The TiPtAu contacts were reletively smooth as-deposited with a measured rms roughness of $9.24 \mathrm{~nm}$ but became very rough after RTA. This contact was formed by an anneal-induced migration of $\mathrm{Pt}$ and $\mathrm{Ga}$ into the $\mathrm{Ti}$ region and at higher temperatures the excess $\mathrm{Ga}$ was outdiffused toward the metal surface.[12] The Au-Ga reaction can then lead to localized spiking and an associated degradation of the surface morphology. With surface roughnesses approaching $90 \mathrm{~nm}$, these contacts were undiserable due to occurances of adhesion problems and delamination during wire bonding[6]. The BeAu contacts to the GaAs cap and InAlAs layers appeared mechanically stable over this range of anneal temperatures with little evidence of spiking. However, the BeAu contacts to the InGaAs layers experienced a rapid increase in surface roughness after RTA at $420^{\circ} \mathrm{C}$. Katz et al. described a deep penetration of the $\mathrm{BeAu}$ into the semiconductor accompanied by outdiffusion of As at similiar anneal temperatures which may have caused the increased metal surface roughness[11]. The semiconductor surfaces were also evaluated and were found to no have nearly identical rms roughness values as the metal surfaces annealled at $360^{\circ} \mathrm{C}$ with no evidence of degradation at any of the anneal temperatures. Therefore, the possibility that the surface roughness are the result of the arise of threading dislocations in the buffer layers seems unlikely.

\section{(b) $1.06 \mu \mathrm{m}$ Device Structure}

A comparison of the specific contact resistances as a function of RTA temperature for contacts to the $1.06 \mu \mathrm{m}$ device structure is shown in Figure 3. Again, the TiPtAu contacts 
deposited on the GaAs/InAlAs and recessed into the InAlAs layers were non-ohmic. On the InGaAs layer the TiPtAu contacts obtained a minimum value of $\rho_{c}=3.57 \times 10^{-3} \Omega \mathrm{cm}^{2}$ at $360^{\circ} \mathrm{C}$.

The BeAu contacts on the InGaAs layer again achieved three orders of magnitude lower $\rho_{c}$ values than the TiPtAu contacts. A minimum $\rho_{c}=1.37 \times 10^{-6} \Omega \mathrm{cm}^{2}$ was reached at the maximum anneal temperature of $420^{\circ} \mathrm{C}$. The increase in $\mathrm{Al}$ concentration of the InAlAs layers in this structure adversly effected our abilities to contact the GaAs/InAlAs and InAlAs layers with the BeAu contacts. Several factors are suspected of contributing to this phenomenon including; increased susceptibility to oxidation of the exposed $\mathrm{Al}$ surface, larger bandgap potential of the $\mathrm{In}_{.10} \mathrm{Al}_{.90} \mathrm{As}$ (2.698 eV compared to $2.018 \mathrm{eV}$ for $\operatorname{In}_{.32} \mathrm{Al}_{.68} \mathrm{As}$ ), and insufficient concentration of In to generate an alloy with the Au at low anneal temperatures[13]. In addition, the lack of stable alloys between $\mathrm{Au}$ and $\mathrm{Al}$ at temperatures below $500^{\circ} \mathrm{C}$ may be indicative of the lack of reactivity of high $\mathrm{Al}$ mole fraction InAlAs that can provide a pathway for Be doping of the InAlAs.

A comparison of the average rms roughness of the contact surfaces as a function of anneal temperature as shown in Figure 4. The TiPtAu contacts to InGaAs behaved identically to those on the $1.32 \mu \mathrm{m}$ device structure with slightly higher rms roughness caused by the increased Ga concentration of the underlying semiconductor. The BeAu contacts to InGaAs were reletively smooth even after the $360^{\circ} \mathrm{C}$ anneal but the surface roughness increased dramatically at the higher anneal temperatures. Again, this could be caused by the higher availability of $\mathrm{Ga}$ in the underlying semiconductor material which resulted in a greater degree of spatial composition variation and spiking. In Figure 5(a-c), we show 3-dimensional atomic force microscopy (AFM) images of the BeAu contact surfaces on InGaAs which were annealled at $360^{\circ} \mathrm{C}, 400^{\circ} \mathrm{C}$, and $420^{\circ} \mathrm{C}$ respectively. The development of spiking and compositional problems were evident with deformations of the semiconductor surfaces on the order of several hundreds of nanometers.

\section{CONCLUSIONS}

The use of BeAu and TiPtAu metallizations for the formation of ohmic contacts to p-type InAlAs and InGaAs has been evaluated for the fabrication of near-infrared optical modulators. BeAu contacts consistantly had lower specific contact resistances than TiPtAu contacts and are 
therefore better suited for use with these materials systems. A comparison between contacts to various layers within the heterostructure showed that the contacts to the InGaAs layers produced specific contact resistance values that were an order of magnitude improvement over contacts made to the InAlAs layers. These were consistant with expectations that the larger bandgap potential of the InAlAs materials would make them more difficult to contact than the InGaAs layers. Also contributing is the difficulty in creating chemical reactions with the predominance of the Group III Aluminum. Specific contact resistances were found to decrease with increasing In concentrations. Further research is required to develop new strategies for ohmic contact formation to InAlAs materials with high concentrations of Al. AFM aquired morphological data suggested a severe degradation of the contact/semiconductor interface at RTA temperatures greater than $360^{\circ}$ and was proportional to the semiconductor Ga concentrations. The lowest values of $\rho_{c}$ occurred with the $\mathrm{BeAu} / \mathrm{InGaAs}$ system for each of our modulator material structures . $\mathrm{A} \rho_{\mathrm{c}}=9.7 \mathrm{X} 10^{-7} \Omega \mathrm{cm}^{2}$ was achieved with RTA at $400^{\circ} \mathrm{C}$ with a minimal amount of surface deterioration for the $1.32 \mu \mathrm{m}$ devices. A $\rho_{c}=3.15 \times 10^{-6} \Omega \mathrm{cm}^{2}$ was achieved with RTA at $360^{\circ} \mathrm{C}$ with a minimal amount of surface deterioration for the $1.06 \mu \mathrm{m}$ devices.

\section{ACKNOWLEDGEMENTS}

The authors would like to acknowledge the expert technical assistance of J.M. Seargent and L. Griego. This work was performed at Sandia National Laboratories supported by the U. S. Department of Energy under contract \#DE-AC04-94AL85000. 


\section{REFERENCES}

1. I. J. Fritz, D. R. Meyers, G. A. Vawter, T. M. Brennan, and B. E. Hammons, Appl. Phys. Lett, 58 (1991) 1608.

2. I. J. Fritz, J. A. Olsen, A. J. Howard, T. M. Brennan, B. E. Hammons, and G. A. Vawter, IEEE J. Quantum Electron. 30 (1994) 452.

3. I. J. Fritz, T. M. Brennan, B. E. Hammons, A. J. Howard, W. Worobey, G. A. Vawter, and D. R. Myers, Appl. Phys. Lett., 63 (1993) 494.

4. I. J. Fritz, B. E. Hammons, A. J. Howard, T. M. Brennan, and J. A. Olsen, Appl. Phys. Lett., 62 (1993) 919.

5. A. J. Howard, A. G. Baca, R. J. Shul, J. C. Zolper, M. E. Sherwin, and D. J. Rieger, Proceedings of the International Workshop on Semiconductor Characterization, (1996) 654.

6. A. J. Howard, P. K. Seigal, R. D. Briggs, D. J. Rieger and A. G. Baca, Proceedings of the International Conference on Metallurgical Coatings and Thin Films, (1996) In the press.

7. H. H. Berger, Solid State Electron., 15 (1972) 145.

8. G. Stareev, A. Umbach, F. Fidorra, and H. Roehle, Proceedings of the Third International Conference on Indium Phosphide and Related Materials, (1994) 264.

9. A. Katz, W. C. Dautremont-Smith, S. N. G. Chu, P. M. Thomas, L. A. Koszi, J. W. Lee, V. G. Riggs, R. L. Brown, S. G. Napholtz, J. L. Zilko, and A. LaHav, Appl. Phys. Lett., 54 (1989) 2306.

10. T. C. Shen, J. Reed, Z. F. Fan, G. B. Gao, and H. Morkoc, Electron. Lett., 27 (1991) 2187.

11. A. Katz, P. M. Thomas, S. N. G. Chu, J. W. Lee, and W. C. Dautremont-Smith, J. Appl. Phys., 66 (1989) 2056.

12. A. Katz, S. N. G. Chu, B. E. Weir, C. R. Abernathy, W. S. Hobson, S. J. Pearton, and W. Savin, IEEE Trans. Electron Devices, 39 (1992) 184.

13. H. Okamoto and T. B. Massalski, in T. B. Massalski (ed.), Binary Alloy Phase Diagrams, Vol. 1, American Society for Metals, Metals Park, OH, 1986, p. 381. 
FIGURE CAPTIONS

Figure 1 - Specific contact resistances versus anneal temperature for BeAu and TiPtAu contacts on $1.32 \mu \mathrm{m}$ transmission modulator heterostructure layers.

Figure 2 - Average rms roughness versus anneal temperature for BeAu and TiPtAu contacts on $1.32 \mu \mathrm{m}$ transmission modulator heterostructure layers.

Figure 3 - Specific contact resistances versus anneal temperature for BeAu and TiPtAu contacts on $1.06 \mu \mathrm{m}$ transmission modulator heterostructure layers.

Figure 4 - Average rms roughness versus anneal temperature for BeAu and TiPtAu contacts on $1.06 \mu \mathrm{m}$ transmission modulator heterostructure layers.

Figure 5 - 3-dimensional AFM images of $\mathrm{BeAu} / \mathrm{In}_{.12} \mathrm{Ga}_{.88} \mathrm{As}$ contacts annealled at (a) $360^{\circ} \mathrm{C}$, (b) $400^{\circ} \mathrm{C}$ and (c) $420^{\circ} \mathrm{C}$ for $30 \mathrm{sec}$. 
Specific Contact Resistance $\left(\Omega \mathrm{cm}^{2}\right)$

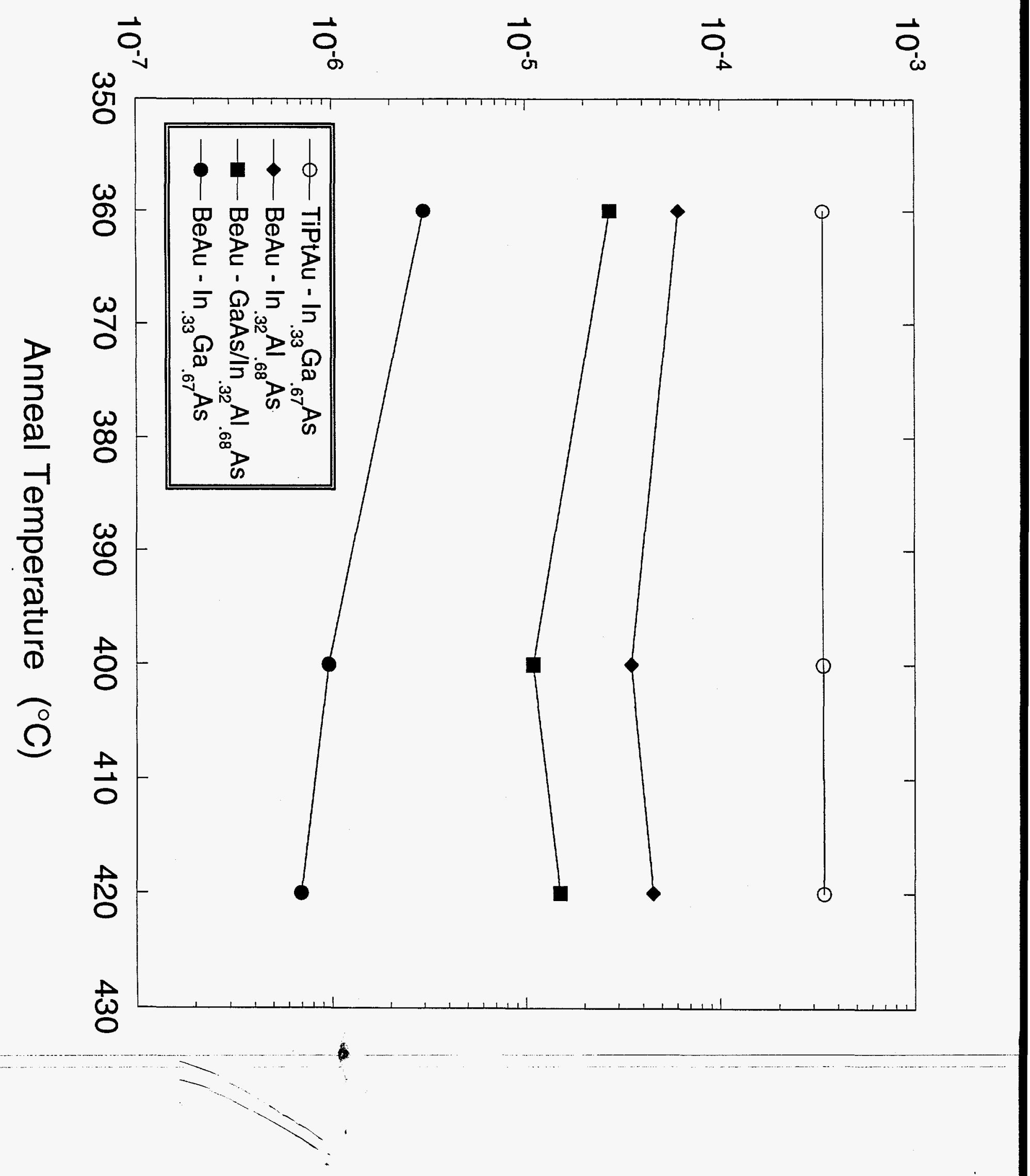




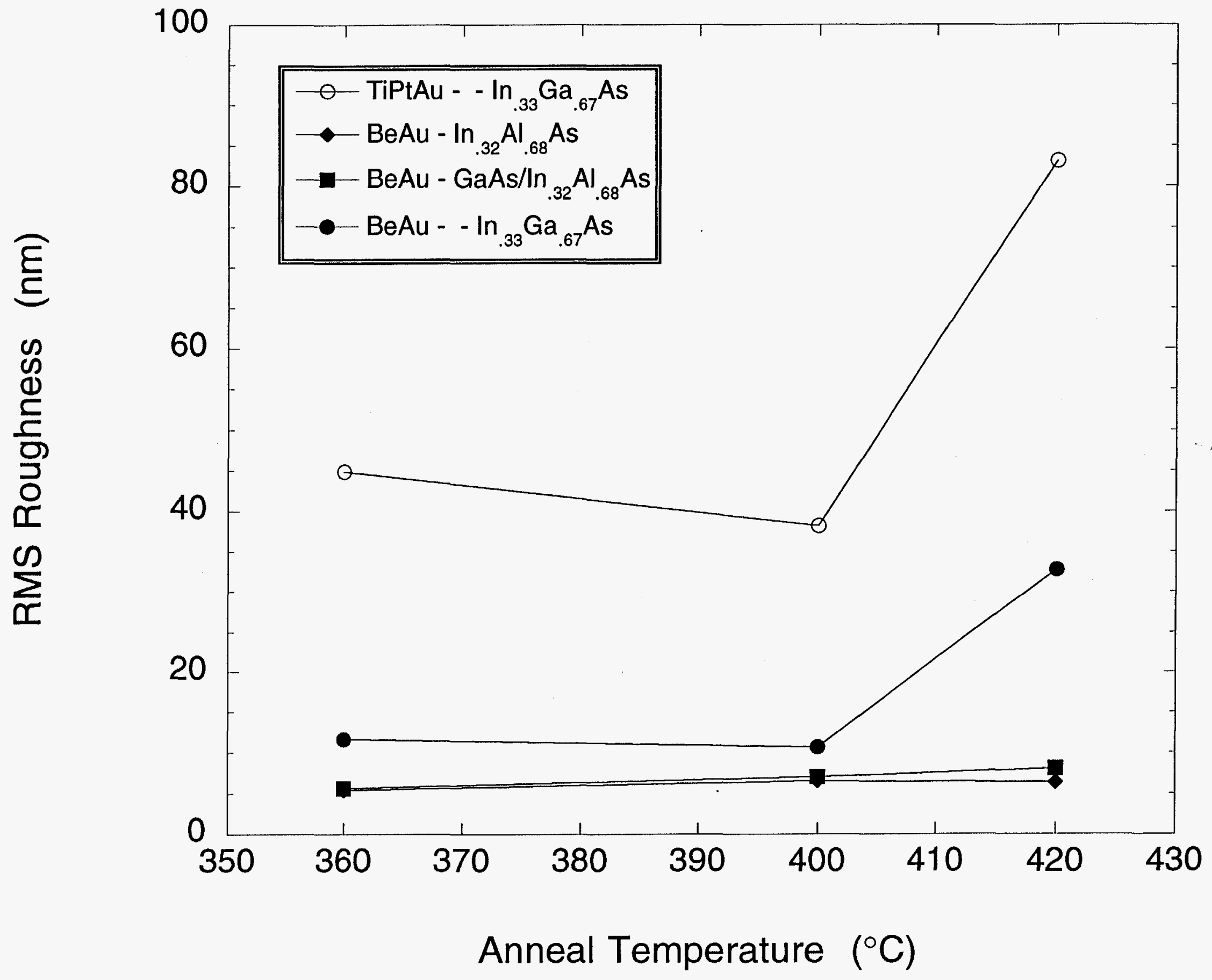


Specific Contact Resistance $\left(\Omega \mathrm{cm}^{2}\right)$

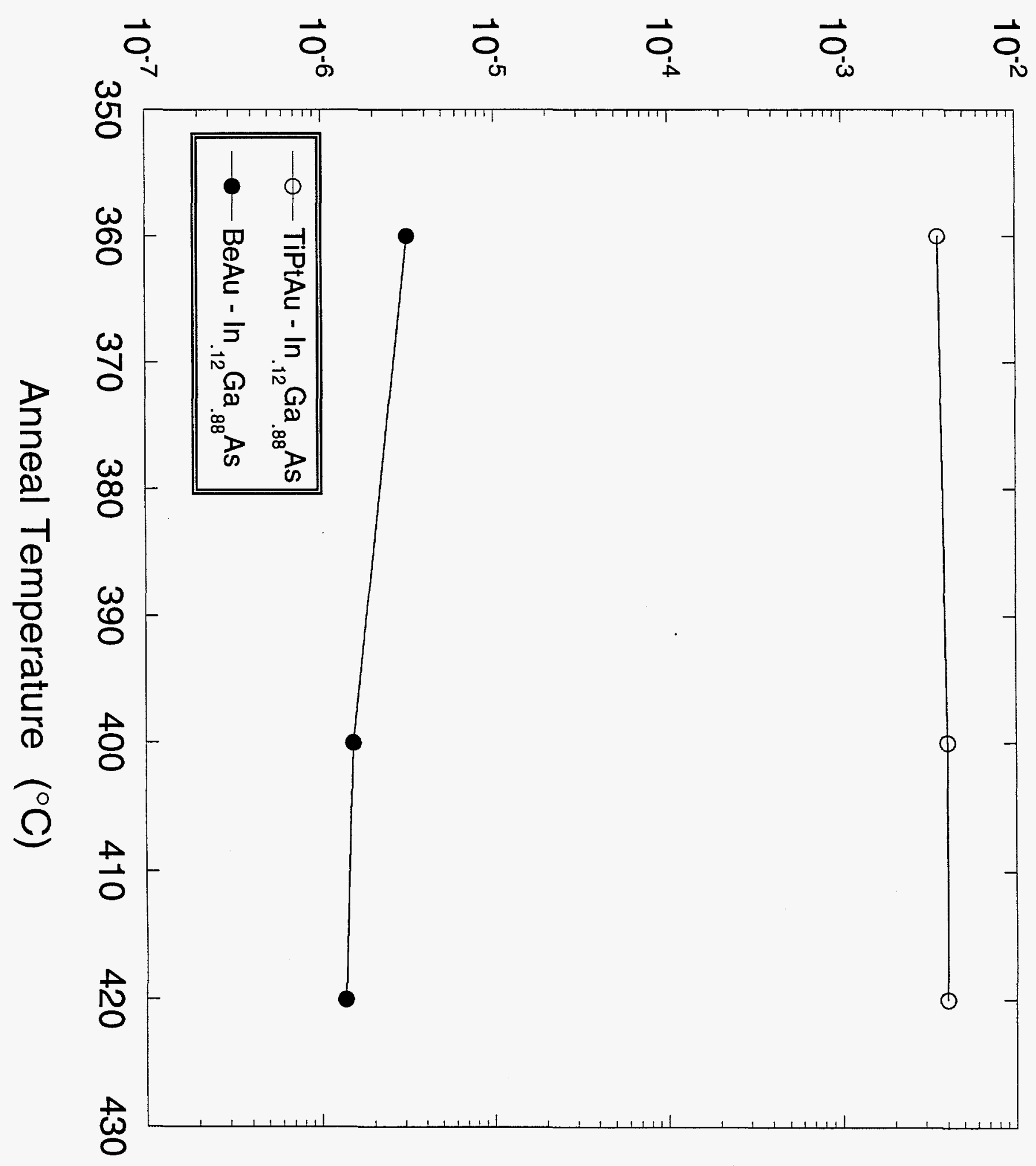




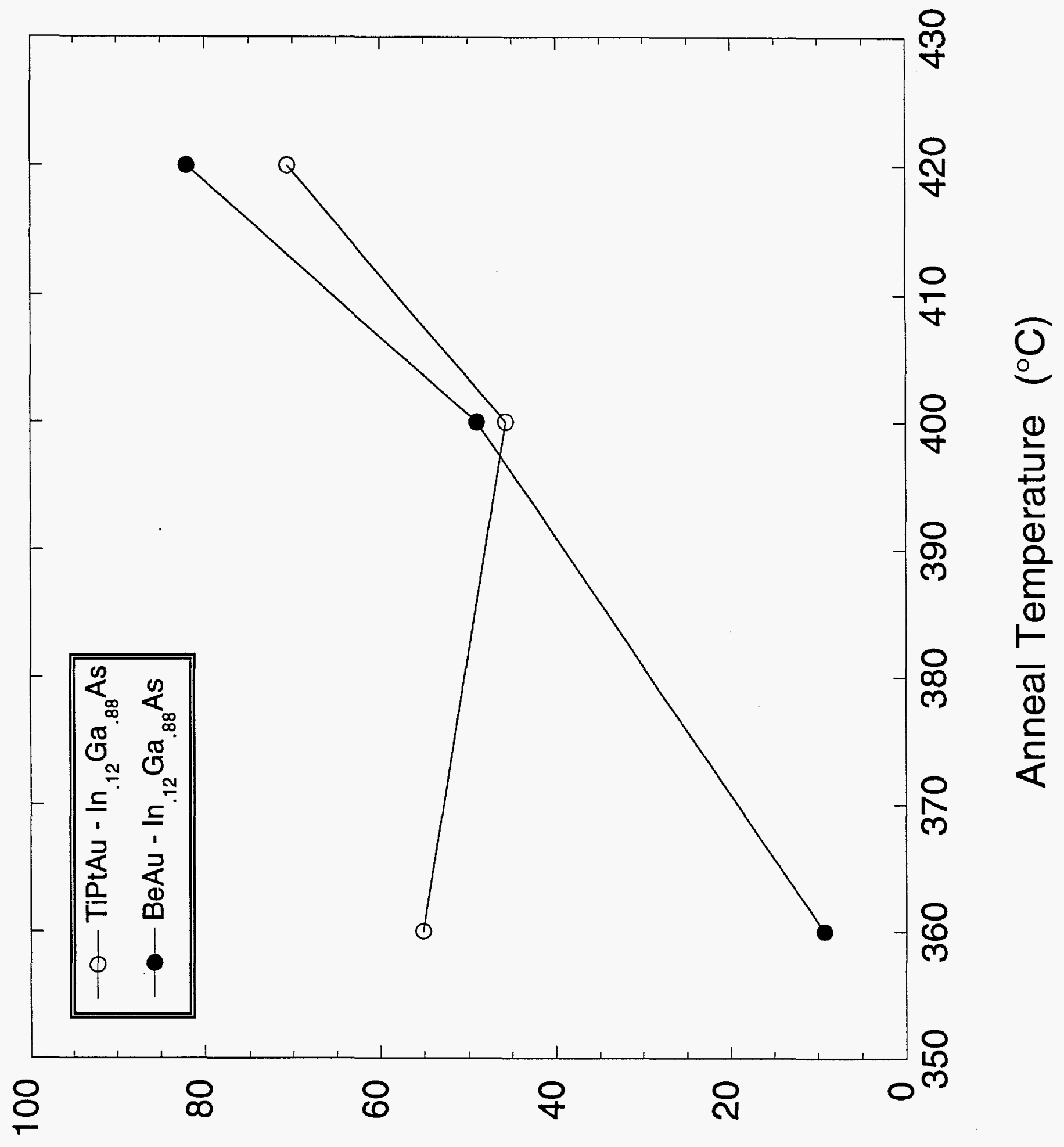

(uu) ssəuybnoy swy 
...

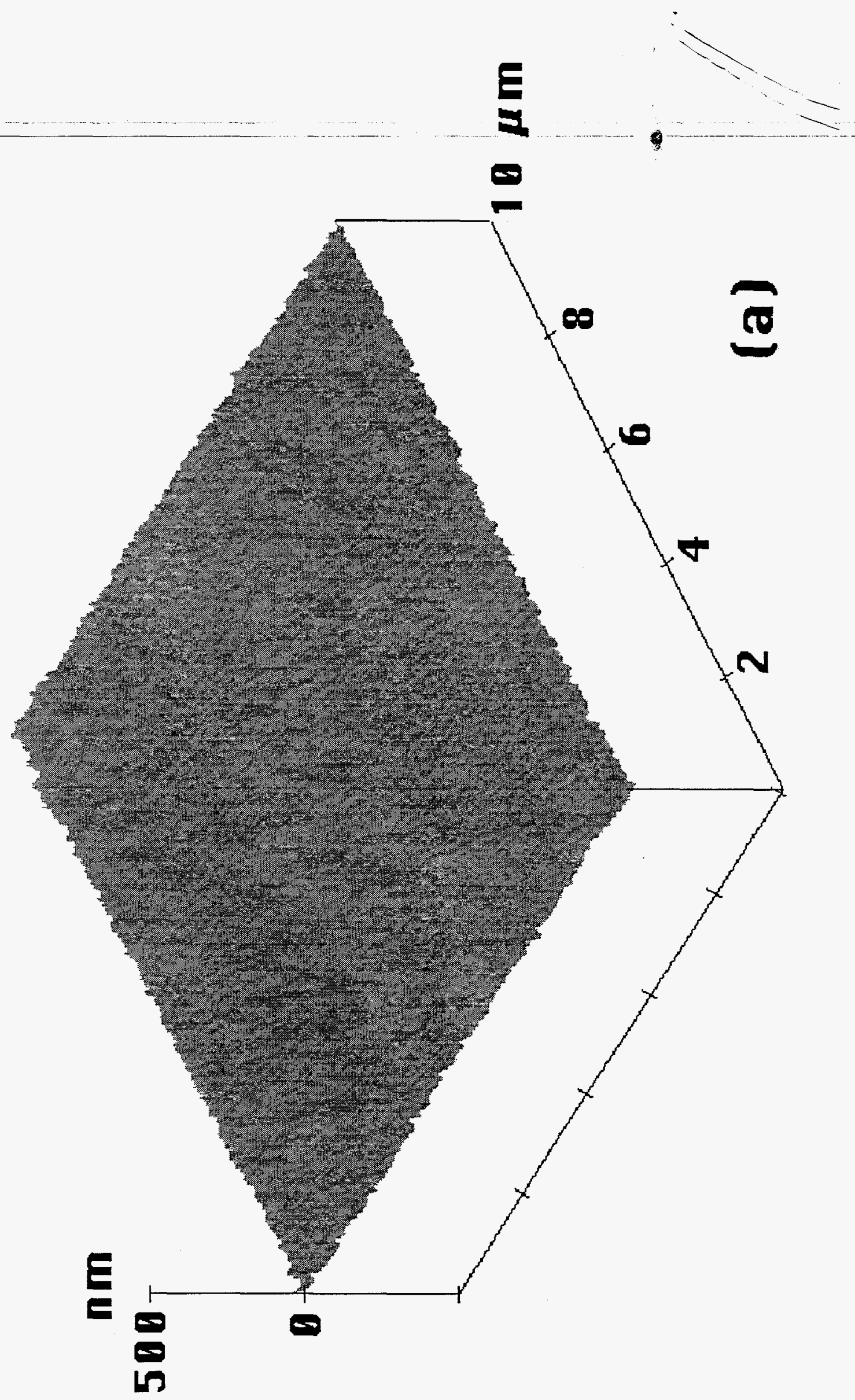



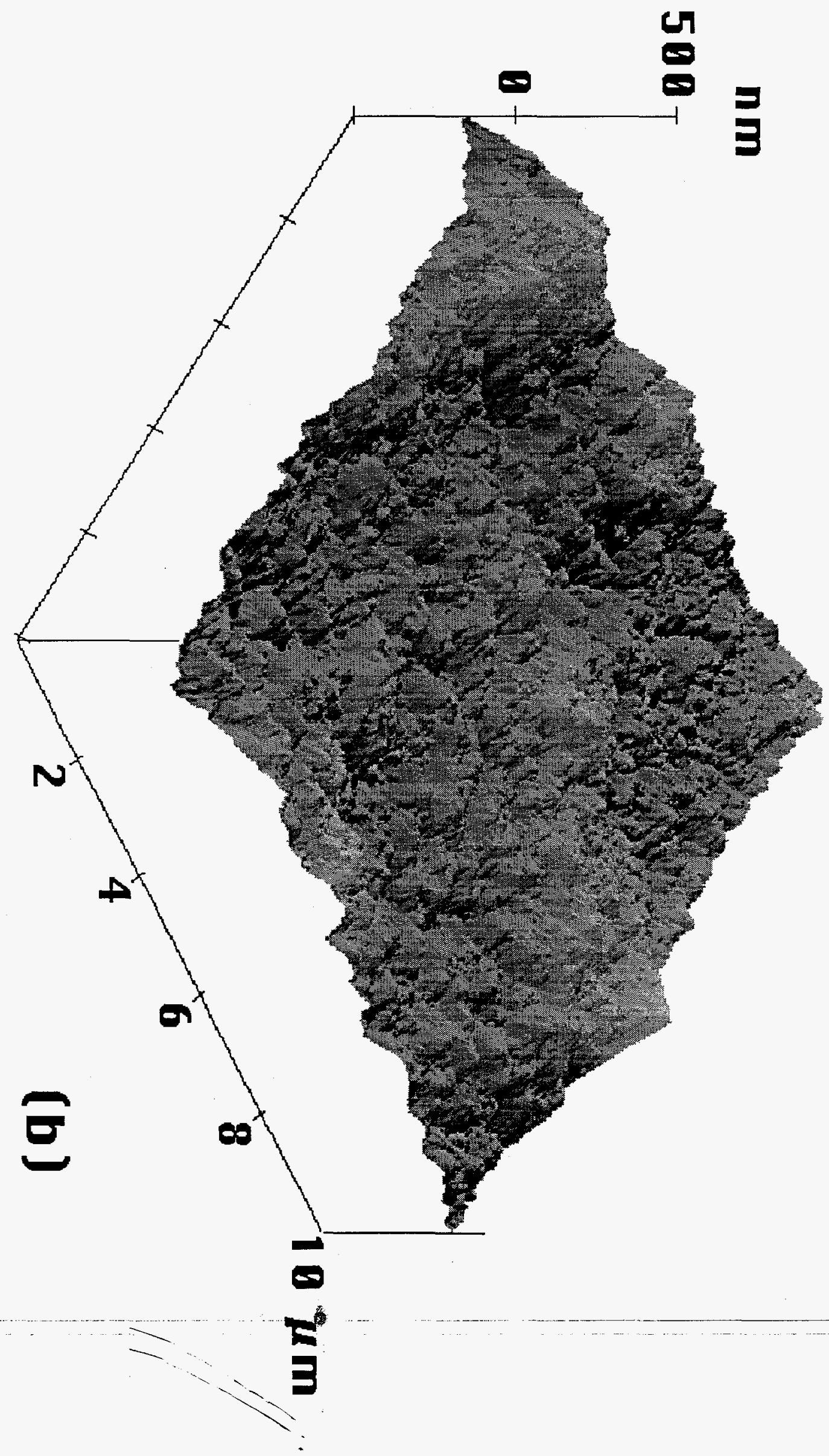


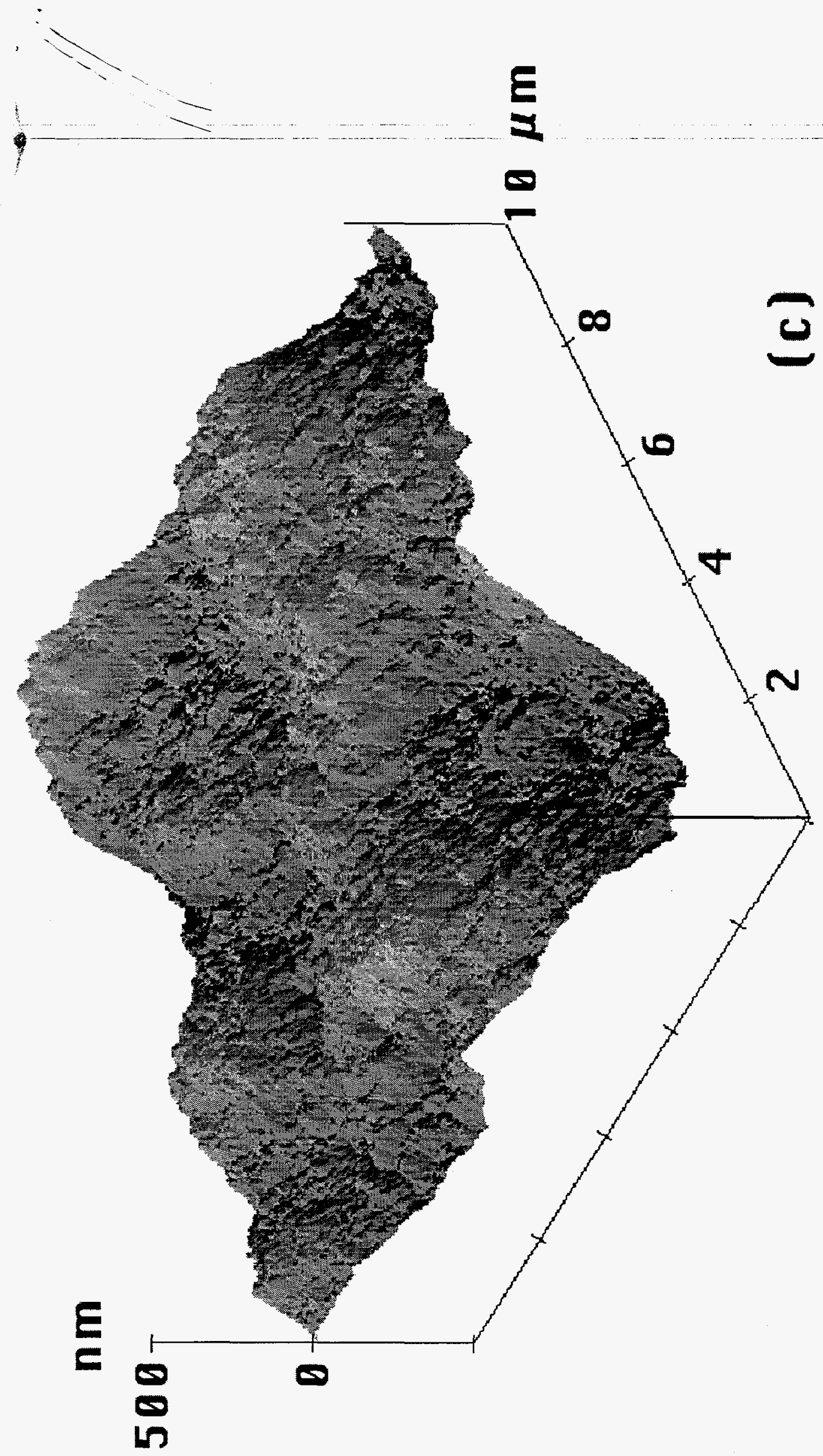

